\title{
Using dynamical seasonal forecasts in marine management
}

\author{
$\underline{\text { C. M. Spillman }}^{\text {a }}$, O. Alves ${ }^{\text {a }}$, D. A. Hudson ${ }^{\text {a }}$, A. J. Hobday ${ }^{\text {b }}$ and J. R. Hartog ${ }^{\text {b }}$ \\ ${ }^{a}$ Centre for Australian Weather and Climate Research (CAWCR), Bureau of Meteorology, \\ Melbourne, VIC 3001, Australia. \\ ${ }^{b}$ Climate Adaptation Flagship, CSIRO Marine and Atmospheric Research, Hobart, TAS 7000, Australia \\ Email: c.spillman@bom.gov.au
}

\begin{abstract}
Seasonal forecasting has great scope for use in marine applications, particularly those with a management focus. Seasonal forecasts from dynamical ocean-atmosphere models of high risk conditions in marine ecosystems can be very useful tools for managers, allowing for proactive management responses on a range of timescales. Applications include coral bleaching risk predictions and forecasts of ocean conditions driving fisheries.

Real-time forecasts for coral bleaching risk on the Great Barrier Reef (GBR) are currently produced operationally using the Bureau of Meteorology's seasonal forecast model POAMA. These forecasts provide an early warning of potential bleaching risk prior to summer, which allows reef managers to both focus monitoring programs and implement strategies to minimise bleaching damage, as well as brief stakeholders. Additionally, probabilistic forecasts provide information as to the likelihood of a bleaching event occurring, which is very useful for management in planning responses and focusing resources.

A second example is the management of the multi-species long-line fishery on the east coast of Australia. Forecasts of ocean temperature from POAMA are used in a statistical tuna habitat model to produce experimental habitat maps for the Australian Marine and Fisheries Authority for use in setting management zones. Seasonal forecasts are also being used to predict ocean conditions for salmon aquaculture farms around Tasmania, with information used by managers to coordinate activities to manage farm health. Probabilistic forecast products for these fisheries are currently under development in consultation with the industry with the aim to produce useful and easily understood management tools.
\end{abstract}

Keywords: Seasonal forecasting, probabilistic forecasts, coral bleaching risk, fisheries management, POAMA 
Spillman et al., Using dynamical seasonal and probabilistic forecasts in marine management

\section{INTRODUCTION}

Climate change is an increasing concern for marine resource managers, with predictions of warming oceans and higher frequency of extreme temperature events (IPCC, 2007). However, interaction with a range of marine industries has indicated that future environmental information over shorter time scales is currently of greater interest. In industry, managers and stakeholders need to make a range of operational decisions on timescales of weeks to months, meaning information on the likelihood of particular conditions in the upcoming season is most useful. Seasonal forecasts from dynamical ocean-atmosphere models of high risk conditions in marine ecosystems can be very useful tools for managers, allowing for proactive management responses. These forecasts can address a knowledge gap previously identified between marine near-nowcasts (timescale of days) and climate model projections (timescale of decades). For effective management, managers need to know the likelihood of particular conditions in the upcoming season rather than today or decades from now. Applications of seasonal forecasting include coral bleaching risk predictions and forecasts of ocean conditions affecting wild fisheries and aquaculture industries.

Real-time forecasts for coral bleaching risk on the Great Barrier Reef (GBR) are currently produced operationally using the Bureau of Meteorology's seasonal forecast model POAMA (Spillman and Alves 2009). These forecasts provide an early warning of potential bleaching risk prior to summer, which allows reef managers to both focus monitoring programs and implement strategies to minimise bleaching damage, as well as brief stakeholders. Additionally, probabilistic forecasts provide information as to the likelihood of a bleaching event occurring, which is very useful for management in planning responses and focusing resources.

Another example of a current seasonal forecasting application is in the management of the Southern Bluefin Tuna (SBT) fishery on the east coast of Australia (Hobday and Hartmann 2006; Hobday et al 2010). Forecasts of ocean temperature from POAMA are used in a statistical tuna habitat model to produce experimental habitat maps for the Australian Marine and Fisheries Authority (AFMA) for use in setting quotas (Hobday et al. 2011). Seasonal forecasts are also being used to predict ocean conditions for salmon aquaculture farms around Tasmania, with information used by managers to coordinate activities to manage farm health (Spillman et al in prep.). Probabilistic forecast products for these fisheries are currently under development in consultation with the industry with the aim of producing useful and easily understood management tools.

This paper describes the scope for seasonal forecasting to play an important role in marine management. Facilitation of seasonal forecast products, both tailored for industry and more general regional forecast products, allows for proactive management and the improved resilience of marine industries to climate change. Here we describe several tailored seasonal forecast products developed at the Bureau of Meteorology and their adoption, use and applicability in marine management.

\section{SEASONAL FORECASTING}

Seasonal prediction schemes, using either statistical or dynamical models, are used to provide forecasts for several seasons into the future. Statistical models use historical data and empirical relationships to predict future events. They can often be quite skilful, though their assumption of climate stationarity means that they may not capture future climate relationships. In contrast, dynamical models such as Global Circulation Models (GCMs), are comprised of differential equations based on the fundamental laws of physics and fluid motion. GCMs, which by nature are multivariate, can simulate system responses to a changing climate, However GCMs can be very complex systems, requiring a detailed understanding of the processes involved,, as well as computationally demanding. Prediction schemes which combine output from both statistical and dynamical models are known as hybrid models and may lead to more accurate predictions than either approach alone.

Predictions on a seasonal timescale are of use to management as they provide an early window for implementation of management strategies to minimise impacts. However, there are several important considerations when designing seasonal products for public use, particularly by industry. A good understanding of who the end user will be and what they need the forecast products for is essential. It is also important to establish what it is that the user wants to know and over what spatial and temporal scale would forecasts be useful. The model must have a certain level of accuracy or skill in the target region in the season of question in order for any forecast products to be useful. Likewise, education of users is critical so that they have an awareness of the strengths and weaknesses of forecast products and the best way in which to 
Spillman et al., Using dynamical seasonal and probabilistic forecasts in marine management

interrogate the predictions. Online delivery of forecasts can be the most effective method of product dissemination though this needs to be combined with appropriate training.

\section{MODEL DESCRIPTION}

The Predictive Ocean Atmosphere Model for Australia (POAMA) is a global seasonal ensemble prediction system (GCM), consisting of a coupled ocean-atmosphere model and initialisation systems for the ocean, land and atmosphere (Spillman and Alves 2009). The system was developed by the Australian Bureau of Meteorology and the Commonwealth Scientific and Industrial Research Organisation (CSIRO), and has been running operationally in real-time since 2002. Current forecast products, both operational and experimental, include ENSO indices, rainfall and ocean temperature. A new version of the system (v2) is currently under development and testing, and will be providing operationally supported forecasts in real-time by the end of 2011. This new system has a number of improvements compared to the current operational system (v1.5), including a new ocean data assimilation system and enhanced initialisation and ensemble generation schemes (Langford et al. 2011). The variability of the results among forecasts for a given forecast issue date gives an indication of the possible spread or uncertainty in the future evolution of the climate system. An ensemble mean is then created by averaging these forecasts. The skill of the system is based on the ability of the model to predict past events and is calculated using a model hindcast dataset (Spillman and Alves 2009).

\section{FORECAST PRODUCTS}

The current suite of marine POAMA forecast products are based on predicted sea surface temperature anomalies (SSTA). These are calculated as the difference between SST values and the relevant climatology. The climatology is defined as the monthly long-term mean SST over the hindcast period (1982-2010 for v2), computed relative to start month and lead-time for the model. To evaluate the accuracy of model forecasts and provide a measure of the skill of the model, SSTA hindcasts are compared to observed SSTA for the same period (Spillman and Alves 2009). Assessment of model performance or skill includes calculation of metrics such as anomaly correlations in time/space (e.g. Fig. 1) and probabilistic measures such as Brier Skill Scores, in addition to comparisons with other models, and evaluation of trend and pattern predictions. The desired level of forecast skill is dependent on the application and there is often lower accuracy in predicting local scale events compared to large climate processes (Spillman et al. 2010).

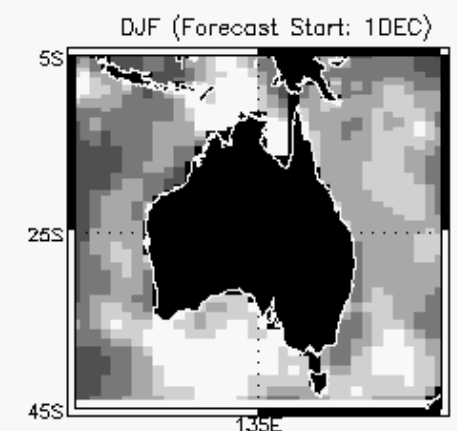

JJA (Forecost Start: 1 JUN)

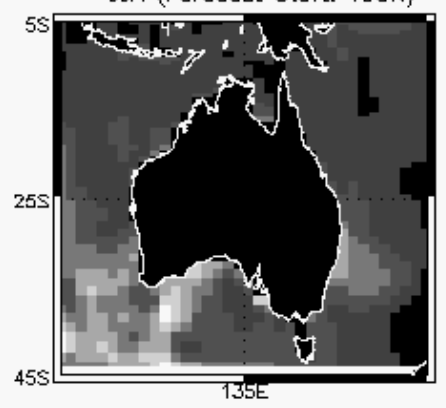

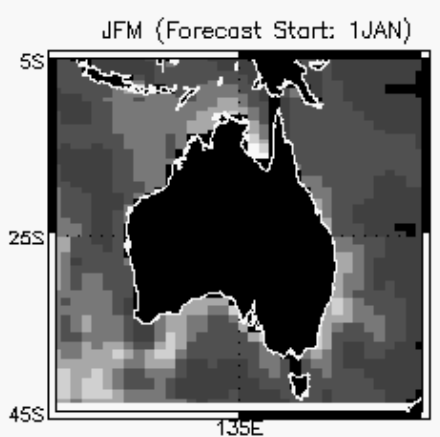

JAS (Forecast Start: 1JUL)

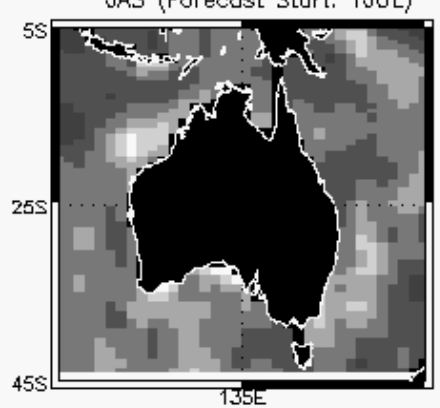

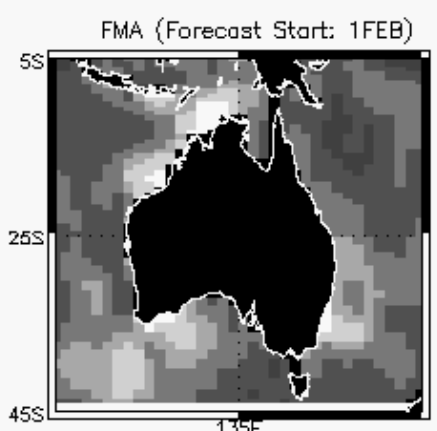

ASO (Forecast Start: 1AUG)

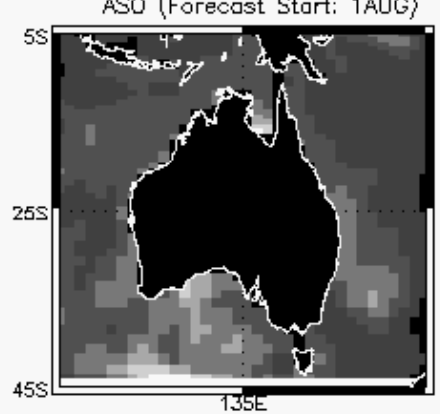

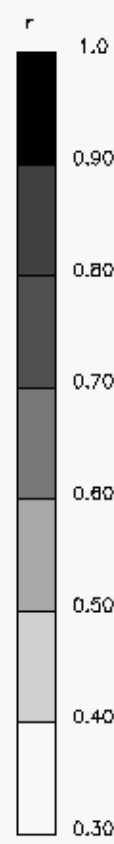

Figure 1: POAMA (v2) anomaly correlations ( $\mathrm{r}=$ correlation coefficient) for forecasts starting on the first of each start month for summer seasons December-January-February (DJF), January-February-March (JFM) and February-March-April (FMA) and winter seasons June-July-August (JJA), July-August-September (JAS) 
and August-September-October (ASO) in the Australian region for 1982-2010. Observed dataset used was Reynolds $1^{\circ}$ SST analysis.

\subsection{Coral Bleaching Risk}

Mass coral bleaching is caused primarily by anomalously warm ocean temperatures. Bleaching results when corals under stress expel their zooxanthellae, giving rise to the typical white coloration. Major bleaching events tend to occur during the summer months, with coral mortality determined by the duration and magnitude of high water temperatures. Both the severity and frequency of such events are predicted to increase under global warming (Hoegh-Guldberg 1999; Baker et al. 2008). The ability to forecast potential ocean conditions that could lead to coral bleaching is a great advancement in the management and conservation of such sensitive systems.

POAMA is currently the only dynamical prediction system used for forecasting coral bleaching on a seasonal time-scale. Two operational POAMA products tailored for the Great Barrier Reef (GBR) are produced daily in real-time and made available for public access. The first is the ensemble mean spatial forecast of SST anomalies across the GBR (e.g. Fig. 2) and the second is the GBR Index, defined as the spatial average of SST anomalies over the region (Spillman 2011). These forecasts have been demonstrated to have useful skill up to three months into the future during the summer months, and captured both the 1998 and 2002 GBR bleaching events (Spillman and Alves 2009). Additionally, a research product showing probabilities of SSTA threshold exceedence in the GBR is also produced. The threshold used is $0.6{ }^{\circ} \mathrm{C}$, a useful management rule of thumb supplied by the Great Barrier Reef Marine Park Authority (GBRMPA). These products are based on the current operational system v1.5 but will be migrated to v2 in the near future.

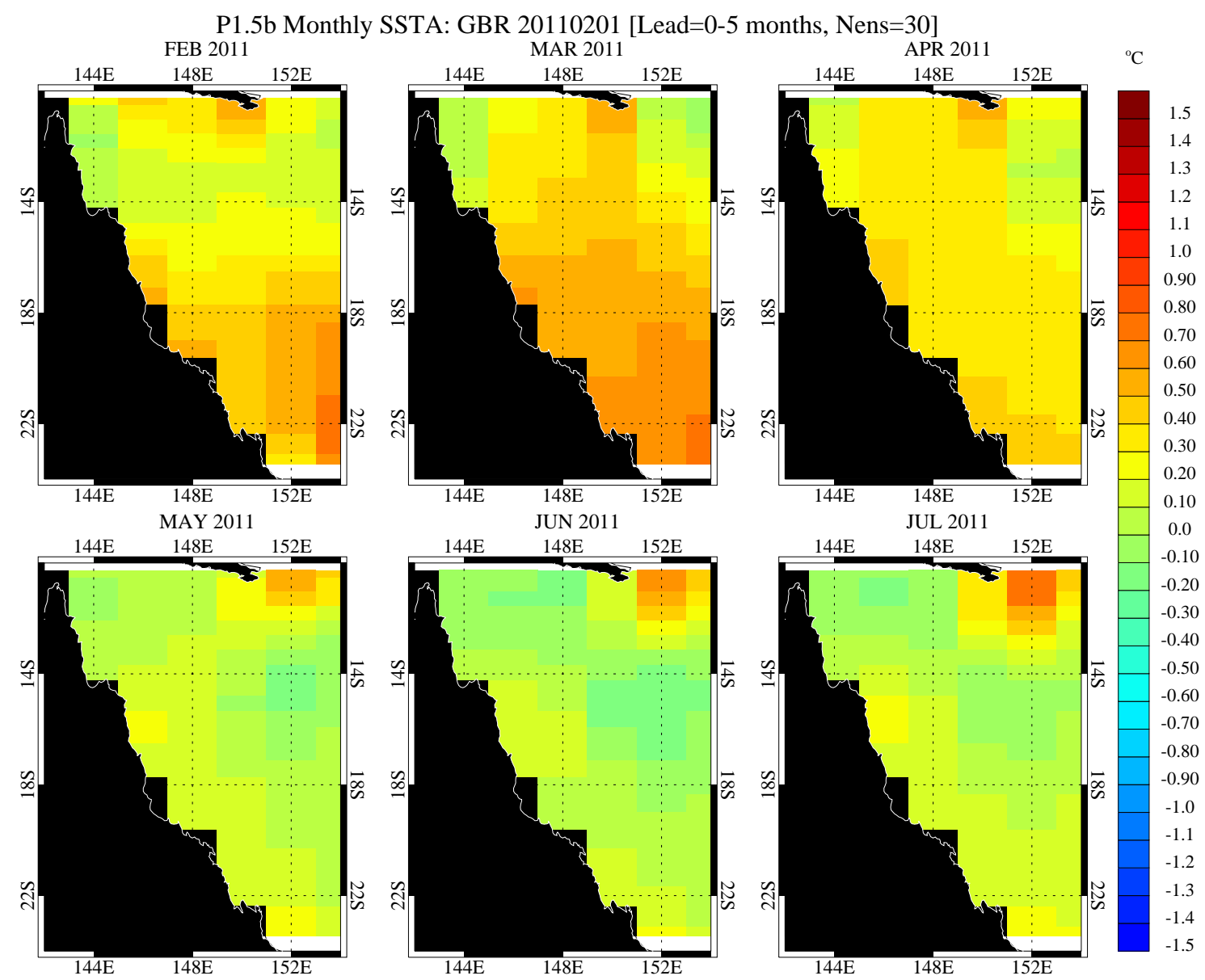

Figure 2: Example of an operational GBR forecast: POAMA ensemble mean forecast of monthly SST anomalies (ensemble mean) for February to July 2011, issued $1^{\text {st }}$ February 2011 (based on 30 daily ensembles). 
Several research SSTA-based products are also produced daily for the tropical oceans and made available for viewing in Google Earth ${ }^{\mathrm{TM}}$. In particular, a new monthly POAMA thermal stress forecast product, Degree Heating Months (DHM), is currently under development. DHM are calculated as the sum of positive SSTA, referenced to the long term highest monthly mean temperature, over a rolling three month time period (Spillman et al. 2011). This forecast product has been demonstrated to capture observed past patterns of thermal stress, including skilful predictions for the severe 1997/98 global and 2005 Caribbean bleaching events (Spillman et al. 2011).

\subsection{Southern Bluefin Tuna Quota Zones}

Southern bluefin tuna (SBT, Thunnus maccoyii) is a quota-limited species in a multispecies longline fishery in east Australian waters. The Australian Fisheries Management Authority (AFMA) regulates the fishery through spatial zones that partition fishing effort, implements quotas and installs observers on board ships in core fishing zones. An important management concern, both domestically and internationally, is minimising capture by nonquota holders, as fish must be discarded if quota is not held (Hobday and Hartmann 2006). Seasonal forecasts can provide valuable insight into future habitat distributions along the east Australian coast for the upcoming months, to better inform operational decisions for this industry (Hobday et al. 2011).
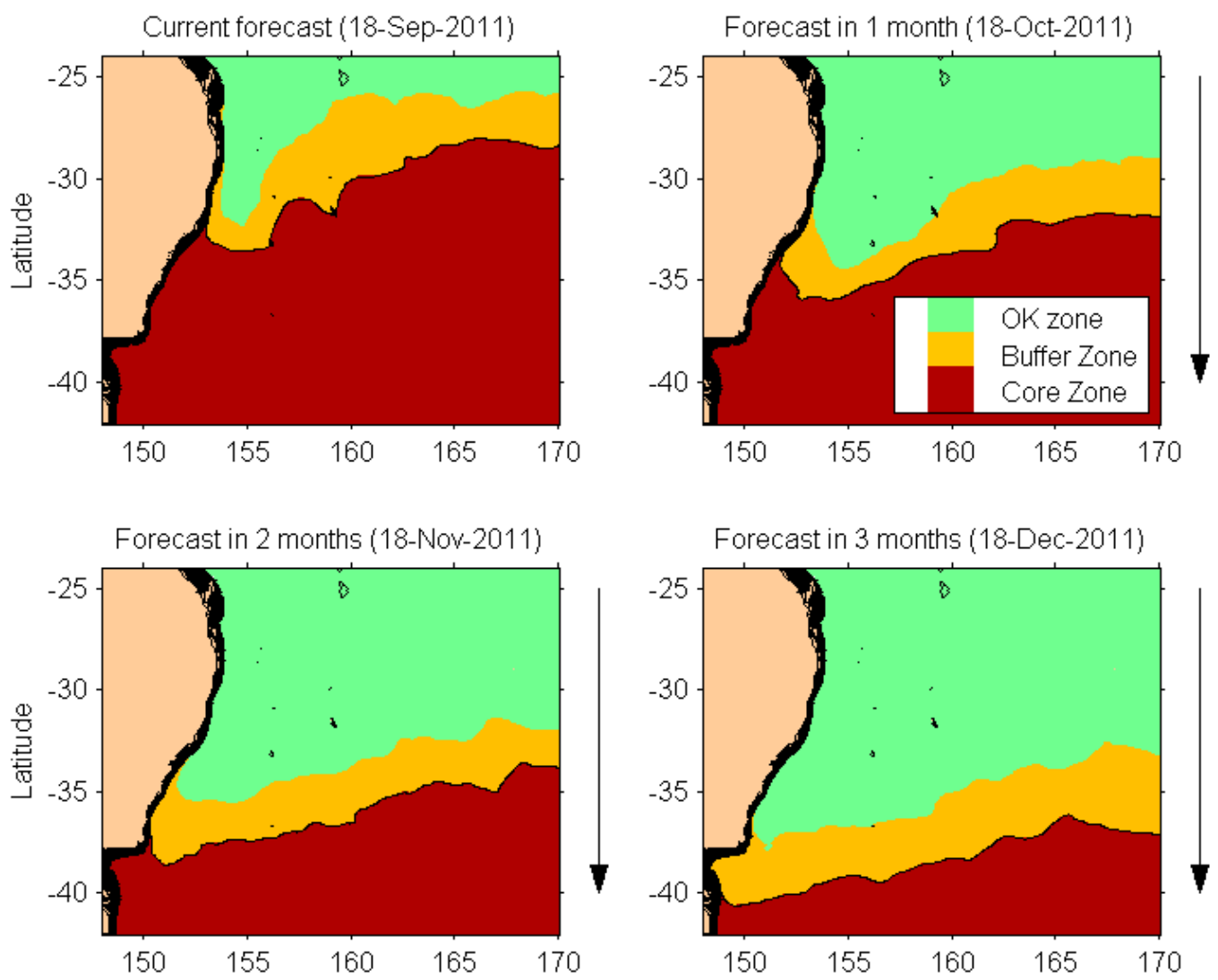

Figure 3: Example map of SBT habitat distribution zones based on POAMA seasonal forecasts. There are three distinct habitat zones: the core zone (red) is defined as the area in which SBT spend at least $80 \%$ of their time based on habitat preferences; the buffer zone (yellow), where SBT spend only 15\% of their time (i.e., the $80 \%-95 \%$ probability region), and the OK zone (green), where SBT are expected to spend less than $5 \%$ of the time (i.e., the $95 \%-100 \%$ probability region) (Hobday et al. 2011). The arrows give an indication of whether the core zone is moving north or south when compared to the previous months forecast.

POAMA forecasts of ocean temperatures down to $100 \mathrm{~m}$ depth are input into a habitat preference model to generated predicted maps of SBT distributions (e.g. Fig. 3). The habitat model has been conditioned with 
Spillman et al., Using dynamical seasonal and probabilistic forecasts in marine management

electronic tag data and provides probabilities of finding SBT at different depths and locations along the east Australian coast, based on fish temperature preferences (Hobday and Hartmann 2006). POAMA derived habitat maps exhibit skill in predicting SBT habitat boundaries, when validated against the current operational real-time system, several months into the future (Hobday et al. 2011). Fortnightly reports are currently produced using the nowcast system during the fishing season (May-November) and also include seasonal habitat forecasts from POAMA. These maps are used by AFMA to restrict fisher access to areas with high predicted SBT distribution, rather than be used as a fish finding tool. The financial benefit of this awareness of future SBT distributions, and how it will influence the decisions of AFMA, is currently being assessed, although feedback from AFMA to date has been positive.

\subsection{Aquaculture}

Salmon aquaculture in Tasmania is a growing industry, worth millions of dollars to the state's economy and is an important regional employer. It also has been identified as an industry vulnerable to climate change (Hobday et al. 2007). Salmon are kept in sea cages for the final two years of production, with salmon health strongly influenced by ocean conditions. Growth is coupled with water temperature, with salmon grown towards their upper thermal limit in summer. Under climate change, this upper thermal limit is predicted to be exceeded more frequently which could result in degraded fish health, increased disease outbreaks and mortality. Advance warning of potentially deleterious ocean conditions would give farm managers time to respond to potentially warm summers and adapt management strategies, e.g. timing of freshwater bathing, nutrition balance and location of ponds, to maximise production.

POAMA forecasts of ocean temperatures around Tasmania are being investigated as a potential proxy for coastal farm temperatures in a scoping study sponsored by industry. The model exhibits useful skill in the region for predicting summer SSTA 1-2 months ahead. There is also some correlation in this region with El Niño Southern Oscillation (ENSO), the East Australian Current and Leeuwin Current and so this information may be used to calibrate and thus improve forecasts. Probabilistic forecast products of SSTA occurring in the upper tercile or exceeding the median will be generated to assist farm managers with risk analysis of different management responses. Monthly reports are currently produced for each farm involved in the study using a statistical forecast scheme, with plans to include POAMA forecasts in the future.

\section{USE OF FORECASTS BY MANAGEMENT}

Seasonal forecasts are a valuable tool in reef and fisheries management, allowing for proactive management responses and the early implementation of preventative measures. POAMA forecasts for the GBR form an important component of the Early Warning System in the GBR Marine Park Authority Coral Bleaching Response Plan (Maynard et al. 2009). The Coral Bleaching Response Plan is a strategic framework comprising of an early warning system and an assessment and monitoring component. The early warning system consists of three stages: climate monitoring, sea temperature monitoring and monitoring of bleaching by the general public and tourist operators. POAMA seasonal forecasts for the GBR form an important part of the first stage, providing outlooks of potential bleaching conditions for the upcoming summer.

Mass coral bleaching itself can not currently be prevented but policies can be implemented to limit reef damage and aid recovery. Management strategies can include limiting access to affected areas to maximise resilience by reducing other stresses e.g., setting temporary Marine Protection Areas, artificially shading or cooling selected local reefs, and enhancing the overall health of the reef by reducing pollution, coastal runoff and overfishing. Currently seasonal forecasts of bleaching risk are most valuable in directing resources and focusing monitoring to increase knowledge of the evolution, causes and consequences of bleaching. Often the first knowledge of coral bleaching in a particular area is after the fact and so the capacity for coordinated monitoring prior to and throughout the bleaching event is invaluable. Briefing government departments and funding bodies, in addition to educating of the general public and tourism industries, are also important uses of the forecasts.

Use of seasonal forecasting is a new development for Australian fisheries. Forecasts can be used to inform management decisions and stakeholders as well as assist in planning quotas and farm activities. Profitable businesses are adaptable businesses and it seems the industry is beginning to recognise this, in addition to potential vulnerabilities to climate change. More work needs to be done on how the forecasts are used and if industry modify their decisions according to forecasts, but at this stage industry are certainly interested in seasonal forecasts products. 
Spillman et al., Using dynamical seasonal and probabilistic forecasts in marine management

\section{CONCLUSIONS}

POAMA forecast products are valuable tools for proactive marine management. There are a number of Australian industries that are currently using, or interested in using seasonal forecast products in their management plans. Education in the use of these tools is very important however so that managers can understand both the strengths and limitations of forecast products and the best way to interpret forecasts. Adoption of products over a period of time is more likely to result in long term benefit, than adoption for a single season. Probabilistic forecasts are important for management in terms of analysing the risk or cost/benefit of implementing a particular strategy. Marine industries are interested in expanding their current management tools, under the realisation that climate change may have both opportunities they could capitalise on and impacts against which they need to increase their resilience. These forecast products can help businesses learn in real-time on the job and provide immediate benefits in terms of climate variability. In the longer term, these seasonal products are an essential tool for better management of sensitive marine systems under climate change.

\section{ACKNOWLEDGMENTS}

The authors would like to thank to the GBRMPA, AFMA and Tasmanian Salmon Growers Association for their support. Thanks also to Amanda Amjadali and Dr Lynda Chambers, both of the Bureau of Meteorology, for their review of previous versions of this manuscript.

\section{REFERENCES}

Baker, A.C., Glynn, P.W., and Riegl, B. (2008). Climate change and coral reef bleaching: An ecological assessment of long-term impacts, recovery trends and future outlook. Estuarine Coastal and Shelf Science, 80, 435-471.

Hobday, A.J., Poloczanska, E.S., and Matear, R. (2007). Implications of Climate Change for Australian Fisheries and Aquaculture: A preliminary assessment, CSIRO Marine and Atmospheric Research. Report to the Department of Climate Change, Canberra, Australia. December 2007.

Hobday, A.J., and Hartmann, K. (2006). Near real-time spatial management based on habitat predictions for a longline bycatch species. Fisheries Management and Ecology, 13(6): 365-380.

Hobday, A.J., Hartog, J.R., Spillman, C.M., Alves, O. (2011) Seasonal forecasting of tuna habitat for dynamic spatial management. Canadian Journal of Fisheries and Aquatic Sciences, 68, 898-911.

Hoegh-Guldberg, O. (1999). Coral bleaching, climate change and the future of the world's coral reefs. Review. Marine and Freshwater Research, 50, 839-866.

IPCC, (2007) Climate Change 2007: The Physical Science Basis. Contribution of Working Group I to the Fourth Assessment Report of the Intergovernmental Panel on Climate Change [Solomon, S., D. Qin, M. Manning, Z. Chen, M. Marquis, K. B. Averyt, M.Tignor and H. L. Miller (eds.)]. Cambridge University Press, Cambridge, United Kingdom and New York, NY, USA.

Langford, S., Hendon, H.H., and Lim, E-P. (2011). Assessment of POAMA's predictions of some climate indices for use as predictors of Australian rainfall. CAWCR Technical Report, 31. ISBN 978-1-92182607-8

Maynard, J.A., Johnson, J.E., Marshall, P.A., Eakin C.M., Goby, G., Schuttenberg, H., and Spillman, C.M. (2009). A strategic framework for responding to coral bleaching events in a changing climate. Environmental Management, 44, 1-11.

Spillman, C.M. (2011). Operational real-time seasonal forecasts for coral reef management. Journal of Operational Oceanography, 4, 13-22.

Spillman, C.M., and Alves, O. (2009) Dynamical seasonal prediction of summer sea surface temperatures in the Great Barrier Reef. Coral Reefs, 28, 197-206.

Spillman, C.M., Alves, O., and Hudson, D.A. (2011). Seasonal prediction of thermal stress accumulation for coral bleaching in the tropical oceans. Monthly Weather Review, 139, 317-331.

Spillman CM, Eakin CM, Donner S (2010) Use of climate models to predict coral reef vulnerability. pp. 3537. In: Nim, C.J. and W. Skirving (eds.), Satellite Monitoring of Coral Reefs in a Changing Climate. NOAA Technical Report CRCP 1. NOAA Coral Reef Conservation Program. Silver Spring, MD. 114 pp. 